\title{
COTIDIANO DO ADOLESCENTE COM DOENÇA CRÔNICA1
}

\author{
Karine Larissa Knaesel Schneider², Jussara Gue Martini
}

\footnotetext{
${ }^{1}$ Artigo elaborado a partir dos resultados da dissertação - O significado da vivência da doença crônica para o adolescente, no Programa de Pós-Graduação em Enfermagem (PEN) da Universidade Federal de Santa Catarina (UFSC), 2010.

${ }^{2}$ Mestre em Enfermagem. Enfermeira do Setor de Internação Pediátrica do Hospital Universitário da UFSC. Santa Catarina, Brasil. E-mail: kalarissa@ibest.com.br

${ }^{3}$ Doutora em Enfermagem. Professora Adjunto do Departamento de Enfermagem do PEN/ UFSC. Santa Catarina, Brasil. E-mail: jussarague@gmail.com
}

RESUMO: Estudo qualitativo que objetivou compreender o cotidiano do adolescente com doença crônica. Os dados foram coletados na Unidade de Internação Pediátrica e no Ambulatório de Pediatria do Hospital Universitário da Universidade Federal de Santa Catarina, com onze adolescentes portadores de doença crônica, entre março e junho de 2009. O Interacionismo Simbólico foi o referencial teórico e a técnica de coleta, a entrevista semiestruturada. Na análise dos dados utilizou-se o Discurso do Sujeito Coletivo. As categorias encontradas foram: o cotidiano da escola, que mostra como o processo de escolarização é alterado, e a importância da participação da escola e instituição hospitalar na promoção da continuidade de sua educação; o cotidiano da alimentação, que aponta as restrições alimentares e necessidade de reeducação alimentar, como aspecto que interfere nas relações sociais, sendo vivenciado com sofrimento; e a alimentação na escola, que mostrou o quanto é difícil para estes adolescentes seguirem sua dieta neste ambiente.

DESCRITORES: Adolescente. Doença crônica. Enfermagem.

\section{DAILY LIFE FOR ADOLESCENTS WITH CHRONIC DISEASE}

\begin{abstract}
This is a qualitative study that aimed to better understand the everyday life of Brazilian adolescents with chronic disease. Data was collected between March and June of 2009 in the Pediatric In-Patient and Outpatient Units at the University Hospital of the Federal University of Santa Catarina, Brazil, involving eleven adolescent patients with chronic disease. Symbolic Interactionism was used as a theoretical reference and semi-structured interviews were used to collect data. Collective Subject Discourse was used to analyse the data, from which the following categories emerged: the school routine, which shows how the schooling process is changed, with the importance of participating in school and the hospital institution promoting the continuation of their education; the feeding routine, which points out dietary restrictions and the need for nutritional education as something that interferes with social relationships, experienced with grief; and school nourishment, which showed how difficult it is for these adolescents to follow their prescribed diet in this environment.
\end{abstract}

DESCRIPTORS: Adolescent. Chronic disease. Nursing.

\section{LA VIDA COTIDIANA DE LOS ADOLESCENTES CON ENFERMEDADES CRÓNICAS}

RESUMEN: Este estudio cualitativo tuvo como objetivo comprender la vida cotidiana de los adolescentes con enfermedades crónicas. La recolección de los datos se hizo en la unidad pediátrica y en la Clínica Pediátrica del Hospital Universitario de la Universidade Federal de Santa Catarina, con once adolescentes con enfermedades crónicas, entre marzo y junio de 2009. Para la fundamentación teórica se empleó el Interaccionismo Simbólico, y la entrevista semi-estructurada fue utilizada para la recolección de los datos. En el análisis de los datos se utilizó el Discurso del Sujeto Colectivo. Las categorías encontradas en el estudio son: la vida cotidiana de la escuela, que muestra cómo el proceso de escolarización cambia, y la importancia de la participación de la escuela y del hospital en la promoción de la continuidad de su educación; la dieta diaria, lo que señala la necesidad de restricciones en la dieta y la educación nutricional, como algo que interfiere en las relaciones sociales, que se experimenta con sufrimiento; y, la alimentación escolar, que demuestra lo difícil que es para estos jóvenes seguir su dieta en este entorno.

DESCRIPTORES: Adolescentes. Enfermedad crónica. Enfermería. 


\section{INTRODUÇÃO}

O cotidiano refere-se à descrição do vivido, ao modo como se organiza o processo de viver dos seres humanos. ${ }^{1}$ Práticas minúsculas, pequenos momentos, acontecimentos triviais e o lazer adquirem importância na vida social. ${ }^{2}$

Neste contexto, a vivência de uma doença crônica ganha relevância, pois afeta o fluxo de vida cotidiana deste adolescente, causando uma ruptura com o mundo social em que se encontra inserido e que é tomado como suposto. ${ }^{3}$ Seu ritmo de vida é alterado e as restrições impostas o impedem de realizar atividades que antes lhe eram permitidas. Neste sentido, exigirá o estabelecimento de ações que permitam reconduzir a vida cotidiana dentro de pressupostos aceitáveis. ${ }^{3}$

A principal característica da doença crônica é a duração. É definida como doença de longa duração, ou seja, uma condição que interfere no funcionamento diário, por mais de três meses em um ano, ou que necessita de um período de hospitalização por mais de um mês, podendo, muitas vezes, ser incurável. ${ }^{4}$ Por esse motivo, deixa sequelas e impõe diversas limitações às funções fisiológicas, ${ }^{5}$ trazendo, ainda, repercussões sociais, emocionais, afetivas, culturais e espirituais. ${ }^{6}$

Nos últimos anos, devido aos constantes avanços tecnológicos na área da saúde como um todo, as doenças crônicas são mais facilmente controladas, o que tem levado a um aumento significativo no número de adolescentes vivendo com elas. ${ }^{7}$

O adolescente que é acometido por uma doença crônica precisa reorganizar sua vida dentro de suas novas possibilidades. Um aspecto frequentemente alterado nesta situação diz respeito à escolarização. A doença, seu tratamento e os efeitos colaterais interferem no desempenho escolar do adolescente, dificultando sua frequência às aulas e sua adaptação escolar. ${ }^{5}$

Outra questão relevante, e que provoca mudanças no cotidiano destes adolescentes, diz respeito à sua alimentação. A doença exige adaptação a restrições alimentares e incorporação de novos hábitos, trazendo dificuldades e sofrimento. O adolescente precisa mudar seu comportamento, seja frente a antigos hábitos, ou em momentos junto aos amigos. ${ }^{8}$

Esta pesquisa teve como objetivo compreender o cotidiano do adolescente portador de doença crônica, sob sua própria ótica. A partir dos resultados, espera-se contribuir para a melhor compreensão das mudanças provocadas pela doença na vida cotidiana do adolescente. $\mathrm{O}$ conhecimento dos significados atribuídos a estas mudanças e de como elas alteram e interferem na realização de atividades diária do adolescente é fundamental para a realização de um cuidado mais amplo, envolvendo ações que contemplem os diversos contextos em que se encontra inserido.

O referencial utilizado para direcionar esta pesquisa foi o interacionismo simbólico, que teve sua origem no pensamento de George Herbert Mead. Este referencial teórico está alicerçado na concepção de que os seres humanos agem em relação aos significados que as coisas têm para eles, significados estes que são construídos ao longo da vida, através da cultura, crenças e valores adquiridos durante os processos de interação. ${ }^{9}$

\section{METODOLOGIA}

Trata-se de uma pesquisa de abordagem do tipo qualitativa descritiva-exploratória, onde se busca respostas a questões privadas, e trabalha-se com o universo de significados e valores relacionados às interações humanas. ${ }^{10}$

A pesquisa foi realizada na Unidade de internação Pediátrica e no Ambulatório de Pediatria do Hospital Universitário da Universidade Federal de Santa Catarina, instituição pública localizada no município de Florianópolis.

Participaram 11 adolescentes na faixa etária de 12 a 17 anos, com diagnóstico de doença crônica, sendo quatro internados na Unidade de Internação Pediátrica e sete que realizavam acompanhamento no Ambulatório de Pediatria, no período de março a junho de 2009.

Não foi feita opção prévia por algum tipo específico de doença como critério de inclusão na pesquisa, visto que o objetivo da mesma consiste em buscar compreender os significados construídos por adolescentes em relação à vivência de uma doença crônica, independente do tipo de patologia.

Os adolescentes selecionados foram os 11 primeiros com os quais a pesquisadora interagiu durante o tempo destinado a coleta de dados, sendo que nenhum se recusou ao estudo. São procedentes da Grande Florianópolis e cidades do interior do estado de Santa Catarina, sendo oito do sexo feminino e três do sexo masculino, com os seguintes diagnósticos de doença crônica: artrite reumatóide juvenil, distúrbio vascular, lúpus eritematoso sistêmico, distúrbio de crescimento, anemia falciforme, diabetes mellitus tipo 1 e doença celíaca. 
A coleta de dados ocorreu no período compreendido entre março e junho de 2009, por meio de entrevistas individuais semiestruturadas, contando com a presença apenas da pesquisadora/ entrevistadora e do adolescente participante. $\mathrm{O}$ local para a realização das entrevistas foi na própria instituição, sendo garantidos a privacidade e o anonimato.

A entrevista constou de duas partes: a primeira, de identificação (sexo, idade, procedência) e a segund,a das questões norteadoras: quando você soube de sua doença? Desde então, como está sendo conviver com ela?

As entrevistas foram gravadas em arquivo do tipo mp3 e, posteriormente, foi feita a transcrição, preservando a veracidade dos depoimentos obtidos.

Para o tratamento e interpretação dos dados utilizou-se o Discurso do Sujeito Coletivo (DSC). ${ }^{11}$ Este discurso é formado pela reunião de diversas Expressões Chaves referentes às Idéias Centrais (ICs) de sentido semelhante ou complementar, e redigido na primeira pessoa do singular, sendo que o "eu" representa um pensamento que, apesar de expresso numa forma individualizada, é socialmente compartilhado, traduzindo melhor a natureza do pensamento coletivo. ${ }^{11}$

Todas as fases desta pesquisa foram fundamentadas na resolução 196/96 do Conselho Nacional de Saúde, e sua execução se deu somente após a apreciação e aprovação do projeto pelo Comitê de Ética e Pesquisa com Seres Humanos das instituições envolvidas, sob o número de protocolo no375/08. O hospital autorizou a coleta de dados em suas dependências, bem como a utilização da

identificação da pesquisadora no estudo. A autorização para participação no estudo foi obtida pelo esclarecimento e assinatura do Termo de Consentimento Livre e Esclarecido pelo representante legal do adolescente, sem suspensão do direito de informação do mesmo, como define a lei 196/96 no que tange às pesquisas envolvendo adolescentes, garantindo proteção à sua vulnerabilidade e incapacidade legalmente definidas. A autorização foi obtida após convite informal e apresentação prévia do projeto de pesquisa.

\section{RESULTADOS E DISCUSSÃO}

Os depoimentos dos adolescentes entrevistados ressaltam a ocorrência de dificuldades no cotidiano escolar decorrentes dos cuidados exigidos pela doença e das limitações, tanto do adolescente frente à escola quanto da própria instituição escolar frente à condição especial deste adolescente. Além disso, outro aspecto que se destacou em suas falas diz respeito às alterações na alimentação, exigidas no convívio com a doença crônica.

Sendo assim, as categorias encontradas foram: O cotidiano da escola, que mostra como o processo de escolarização é alterado, e a importância da participação da escola e instituição hospitalar na promoção da continuidade de sua educação; $\mathrm{O}$ cotidiano da alimentação, que aponta as restrições alimentares e necessidade de reeducação alimentar como aspecto que interfere nas relações sociais, e A alimentação na escola, que evidencia o quanto é difícil para estes adolescentes seguirem sua dieta neste ambiente.

\section{Primeira categoria: o cotidiano da escola}

a) Repetência do ano escolar devido às internações frequentes

b) Dificuldades na aprendizagem devido à doença

c) A falta de conhecimento da escola

d) A dificuldade para se estudar no hospital

e) A importância da participação da escola

Quadro 1 - Idéias centrais da categoria - O cotidiano na escola.

A escola é um espaço marcante na vida dos adolescentes, sendo campo de vários tipos de aprendizagem e de relacionamentos interpessoais. Além de representar a primeira instituição a manter contato com o adolescente, ela proporciona a experimentação da formação da identidade para além da família. A escola exerce papel significativo na transição de desenvolvimento da infância para a adolescência. Ela possui uma função identitária, contribuindo na promoção do desenvolvimento psicológico do adolescente, à medida que ele começa a se reconhecer como parte de um grupo e compartilhar significados que irão influenciar fortemente em sua identidade pessoal. ${ }^{12}$

O afastamento do ambiente escolar, em função da hospitalização, é uma situação que assume importância relevante no caso de adolescentes com doença crônica, pois, muitas vezes, as internações repetitivas em um curto espaço de tempo levam a sérias dificuldades no acompanhamento do ano 
escolar. Os adolescentes demonstram tristeza ao falar dos períodos de afastamento do ambiente escolar em razão do adoecimento. Preocupam-se com a perda do ano letivo, que representa um acontecimento frequente em seu cotidiano, visto que o mesmo não encontra alternativas disponíveis para, de alguma forma, continuar desenvolvendo seus estudos durante o período de internação.

\section{IC - Repetência do ano escolar devido as interna- ções frequentes}

DSC: [...] quando eu tenho que ficar internada, aí eu não vou na aula, já repeti, no ano que eu internei bastante vezes [...] eu não tinha aprendido nada, eu ficava dois meses em casa e dois meses eu vinha pra cá, aí eu repeti, é difícil, não dá pra acompanhar a escola.

Além das hospitalizações frequentes e da necessidade de tratamento, os próprios sinais e sintomas da doença alteram o desempenho do adolescente, prejudicando seu aprendizado e levando ao atraso escolar. As restrições inerentes à doença crônica são diversas, e as perdas escolares decorrentes não só afetam o momento de vida atual deste adolescente, como também poderão desencadear uma série de problemas em sua vida adulta. ${ }^{13}$

Ficou evidenciado nos depoimentos que, mesmo quando conseguem manter sua frequência nas aulas, ainda assim o aprendizado e rendimento escolar são afetados pela doença. A indisposição física e as recidivas são fatores constantes no dia-a-dia destes adolescentes, interferindo na sua qualidade de vida e pleno desenvolvimento. Além da dificuldade em obter um grau de instrução, a descontinuidade da vida escolar pode atingir as relações sociais e até mesmo os sonhos desses adolescentes. $^{8}$

\section{IC - Dificuldades na aprendizagem devido à do- ença}

DSC: [...] eu tenho dificuldade de gravar, antes eu ia bem nas provas, agora não consigo gravar. No ano passado rodei de novo, é porque quando não tá boa tu não tem como se concentrar, porque daí te dá sonolência, te dá sede, tu não tem como se concentrar, aí foi onde eu rodei.

As dificuldades em acompanhar o ano escolar e o rendimento dos colegas de sala podem levar o adolescente a se sentir desmotivado e influenciar negativamente em sua autoestima, ao comparar-se com seus colegas. A autoimagem prejudicada acaba por levar a dificuldades nos relacionamentos, especialmente no contexto social da escola. ${ }^{13}$
Considerando o papel fundamental que a escola exerce na vida desses adolescentes, é de extrema importância que os profissionais envolvidos no ensino, bem como a própria instituição, estejam capacitados para lidar com as possíveis situações que permeiam o seu cotidiano. A escola deve ser um espaço de fortalecimento, apoio e cuidado, devendo contribuir para o bom desenvolvimento do aluno. A falta de conhecimento sobre suas condições de saúde, necessidades e limitações podem trazer consequências importantes ao mesmo. O despreparo da escola para atender as necessidades deste adolescente vem transformando um ambiente que deveria ser sua principal fonte de apoio social em um ambiente estressor. ${ }^{13}$

\section{IC - A falta de conhecimento da escola sobre a situação de vida do aluno}

DSC: [...] eu nunca perdio ano, mas eu ia rodar por causa de faltas na aula porque eu tava internada, aí a minha mãe foi reclamar e nenhum professor sabia que eu tinha uma doença, aí eu fiquei internada, todo mundo me deu falta. A minha mãe já tinha falado pra diretora da minha doença, mas ela não passou pra coordenadora, nem pra ninguém, tanto que teve um dia que eu tava passando mal, tava vomitando e tudo e ninguém sabia o que fazer.

O acompanhamento escolar da criança/ adolescente hospitalizado é previsto por meio da Política Nacional de Educação Especial, de 1994, ${ }^{14}$ através da implantação da classe hospitalar. Esta prática pedagógica, que ocorre em ambientes de tratamento de saúde, objetiva garantir a continuidade do ensino formal e do desenvolvimento cognitivo, além da manutenção do vínculo com as escolas por meio de um currículo flexibilizado e/ ou adaptado. $\mathrm{O}$ acesso à educação é um direito definido em lei e, em situações onde circunstâncias impedem a frequência escolar, como é o caso das repetitivas internações dos adolescentes com doença crônica, o processo de aprendizado deve ser promovido e incentivado. O cuidado no ambiente hospitalar deve ultrapassar os aspectos biológicos e o tratamento da doença. O enfermeiro pediátrico deve buscar lutar, juntamente com as famílias, pela implantação de formas alternativas de oferta de ensino na instituição. Por outro lado, nos hospitais que já contam com este serviço, é papel importante do enfermeiro articular-se com o professor da classe hospitalar, estabelecendo uma parceria de forma a conhecer o trabalho desenvolvido pelo mesmo, bem como explicar a dinâmica e o funcionamento da unidade e inseri-lo na equipe de saúde. 
No hospital onde se realizou a pesquisa ainda não há implantação efetiva da Classe Hospitalar, o que aumenta as dificuldades em manter esse acompanhamento e o aprendizado do adolescente. A tentativa de estudar sozinho normalmente é frustrante. O adolescente hospitalizado precisa de apoio e estímulo para que possa dar continuidade ao seu estudo, pois o processo de hospitalização representa um momento difícil e que demanda mobilização de energia para o seu enfrentamento e adaptação.

\section{IC - A dificuldade para se estudar no hospital}

DSC: [...] quando tá no hospital não dá pra estudar. Minha mãe diz que vai trazer o material, mas não dá [...], não tem energia, não dá ânimo, você começa a ler, ler, mas não entra na cabeça, então prefiro estudar em casa [...].

É fundamental que os pais compreendam a importância dos estudos para seus filhos e que o hospital faça parcerias com profissionais especializados, de modo a promover a continuidade da educação. ${ }^{8}$ Educação e saúde devem ser pensadas e trabalhadas de maneira conjunta. É preciso refletir, tanto sobre a necessidade de formação e atuação de professores em hospitais, quanto de profissionais de saúde em instituições escolares. O trabalho articulado se faz necessário para um melhor e mais efetivo cuidado ao adolescente com doença crônica.

\section{IC - A importância da participação da escola}

DSC: [...] tinha professora que era boazinha, que entendia o meu problema. Quando eu tava internado ela mandava apostila, prova pra eu fazer, mas aí, outra, não.

Outro ponto a ser trabalhado diz respeito ao convívio com os demais alunos e colegas de sala. Neste sentido, considera-se que a falta de entendimento sobre as implicações da doença e as necessidades deste adolescente podem ser fonte de conflitos e dificultar sua inclusão no grupo escolar. O adolescente pode ser rotulado como diferente, devido às necessidades especiais que sua doença demanda.

DSC: [...] tem aqueles que nunca respeitam [...] dá vontade de ir no banheiro toda hora e tem gente que não respeita [...] tem regras no colégio para ir ao banheiro e beber água e os professores me liberam [...] daí muita gente acha que isso é privilégio, não porque eu preciso.

O contexto demonstra e reforça a necessidade de educação em saúde junto aos professores e colegas de adolescentes com doença crônica, por meio da atuação dos profissionais de saúde nas escolas. São muitas as situações que podem desmotivar este adolescente e prejudicar seu ajustamento escolar, sendo de extrema importância o conhecimento de seu cotidiano, para que a comunidade escolar possa então colaborar com o cuidado ao mesmo, proporcionando um ambiente favorável ao desenvolvimento de suas potencialidades.

\section{Segunda categoria: o cotidiano da alimentação}

\begin{tabular}{|l|l|l|}
\hline $\begin{array}{l}\text { a) A tristeza devido às restrições ali- } \\
\text { mentares, os outros podem e eu não }\end{array}$ & $\begin{array}{l}\text { b) Quando saio com amigas descuido da } \\
\text { alimentação, como o mesmo que elas }\end{array}$ & $\begin{array}{l}\text { c) O cuidado com a alimentação in- } \\
\text { terfere nas atividades e amizades }\end{array}$ \\
\hline $\begin{array}{l}\text { d) Não é fácil mudar os hábitos ali- } \\
\text { mentares }\end{array}$ & e) A falta de apoio da família e dos amigos & f) A alimentação em casa \\
\hline $\begin{array}{l}\text { g) Com o tempo fui aprendendo a } \\
\text { me controlar, hoje consigo lidar me- } \\
\text { Ihor com minha alimentação }\end{array}$ & $\begin{array}{l}\text { h) Tenho estratégias para poder comer o } \\
\text { que quero. }\end{array}$ & $\begin{array}{l}\text { i) Faço brincadeiras com a minha } \\
\text { dieta }\end{array}$ \\
\hline
\end{tabular}

Quadro 2 - Idéias centrais da categoria - O cotidiano da alimentação.

Outro aspecto que permeia o cotidiano do adolescente com doença crônica refere-se ao cuidado com a alimentação. As restrições neste campo são vivenciadas com sofrimento, e os depoimentos refletem o quanto é difícil incorporar novos hábitos alimentares, resistindo ao desejo de comer o que gostam e na quantidade que desejam.

IC - A tristeza devido às restrições alimentares, os outros podem e eu não
DSC: [...] fico chateada quando tenho vontade de comer alguma coisa e não posso. Até na páscoa a minha madrinha nem me deu chocolate, me deu dinheiro. Eu gostava de comer doce [choro]. No colégio [...], em festa [...], não podia comer, todo mundo comia [muito choro]. Às vezes você quer atacar um prato de macarrão, mas não pode porque tem uma determinada quantidade [...] têm que se sustentar com aquilo que tem. Então é ruim quando tu vai sair e vêalguém comendo, aí a gente pensa né, porque que eu não posso comer? 
O estilo de vida dos adolescentes sofre diversas influências, como as exercidas pelo convívio familiar, amigos, mídia e pressão social. ${ }^{8}$ É preciso haver força de vontade e disciplina para manter uma rotina alimentar diferente das outras pessoas. $\mathrm{O}$ adolescente sente-se triste, diferente dos outros e injustiçado por ser o "único" privado de alimentar-se normalmente, sendo que em alguns momentos, em especial aqueles de lazer com os amigos, acaba por ceder aos desejos alimentares, embora consciente das repercussões que isto poderá lhe causar.

\section{IC - Quando saio com amigas descuido da alimen- tação, como o mesmo que elas}

DSC: [...] quando vou no shopping, aí eu como a mesma coisa que elas, [...] como é que eu vou escolher um sanduíche natural ao invés de um lanche! Eu já escolhi um sanduiche natural uma vez, mas foi com a minha avó. [...]. Hoje eu trouxe meus exames e estão al tos, foi por causa da alimentação [...] eu tava saindo bastante, tinha bastante festa daí às vezes eu esquecia [...] comia fora do horário, comia salgadinho, coisa assim.

Os cuidados exigidos com uma dieta especial e as restrições alimentares interferem na vida social e no cotidiano destes adolescentes, pois a comida é peça chave de encontros e comemorações, trazendo consigo significados que vão muito além do simples ato de comer. Assim, a doença limita a participação do adolescente na atividade do grupo, tornando difícil pertencer ao mesmo, interferindo em suas amizades e trazendo dificuldades para o seu convívio social.

O adoecimento, na adolescência, se constitui em um fenômeno causador de inúmeras modificações de ordem objetiva e subjetiva, podendo significar para o adolescente um não ser igual. Neste contexto, ele passa de uma condição de saudável ou normal para portador de uma doença e diferente de seu grupo. ${ }^{15}$

Durante momentos de encontro com os amigos, torna-se ainda mais difícil para o adolescente lidar com as restrições alimentares, pois, além de estar em situações onde há uma oferta de alimentos tentadores, existe ainda o agravante de não querer ser diferente dos demais colegas do grupo. Nesta fase da vida o grupo assume um papel muito importante, é nele que o adolescente busca afirmação e valorização para desenvolver sua autoconfiança, o senso de identidade de grupo é essencial no desenvolvimento de um senso de identidade pessoal.
IC - O cuidado com a alimentação interfere nas atividades e amizades

DSC: [...] qualquer lugar que tu vai, quando tem que ficar na casa de alguém tem que levar comida, coisa assim [...]. Qualquer lugar que meus amigos vão, às vezes não dá pra eu ir, se eles querem comer uma pizza daí já não dá pra mim ir, por isso que é mais difícil [...].

Os adolescentes destacam em seus depoimentos, que este é um processo lento e contínuo, permeado de muitas dificuldades. Demonstram ter consciência do que já conquistaram, mas se cobram pelos hábitos que ainda não conseguiram mudar, colocando a comida como um dos aspectos mais difíceis de serem incorporados.

A incorporação de novos hábitos alimentares e de vida, e a introdução de uma nova rotina a ser seguida, acarretam consequências ${ }^{16}$ que podem ser mais difíceis de serem vivenciadas e trabalhadas na adolescência devido a questões como nível de maturidade, necessidade de independência e autonomia, valorização e senso de identidade de grupo e a idéia de indestrutibilidade. A maioria dos adolescentes interpreta os fatos de acordo com o que eles significam no presente, não considerando as consequências que os mesmos poderão trazer no futuro. Assim, não reconhecem os cuidados preventivos como prioridade, assumindo um comportamento caracterizado por muitos como irresponsável e descompromissado. ${ }^{17}$ No entanto, este tipo de comportamento tem sido relatado como típico desta fase e o adolescente, muitas vezes, tem dificuldades em medir as consequências de seus atos.

\section{IC - Não é fácil mudar os hábitos alimentares}

DSC: [...] eu acho que foi isso que eu errei tanto e erro até hoje. Já faz sete anos que eu to convivendo com isso, que eu tento me corrigir [...]. Os anos passame as coisas mudam, não é uma mudança imediata [...] imagina anos fazendo a mesma coisa e de repente ter que mudar. É um processo que demora, você ter um estilo de vida, um hábito de vida e num estalar de dedos você tem que mudar tudo. É difícil, só com o tempo tu vai aprendendo a conviver [...] Além disso, quando a gente é mais nova não consegue ter essa visão [da importância da prevenção] e acaba não se cuidando.

Para a efetiva incorporação dos bons hábitos alimentares é necessário que o adolescente compreenda a importância de uma alimentação adequada para o cuidado e controle de sua doença, colaborando na manutenção da saúde e na melhora da qualidade de vida. Ele necessita de ajuda e orientação para perceber o valor deste cuidado, 
sendo de fundamental importância o estabelecimento de uma relação de confiança e apoio com seu círculo de convivência. $\mathrm{O}$ adolescente precisa perceber nestas pessoas uma real preocupação com suas necessidades e ansiedades. No entanto, muitas vezes, eles acabam por se deparar com situações onde as pessoas não demonstram estar sensíveis às suas necessidades. ${ }^{8}$

\section{IC - A falta de apoio da família e dos amigos}

DSC: [...] os que diziam ser meus amigos eram os que me ofereciam mais doces, me chamavam pra fazer lanche [...] sabendo que tu não pode [...]. Imagina, chegar em casa, no dia que você chegou do hospital e ver ela [a tia] fazendo bolo de chocolate e um monte de balas, sabendo que você não pode e ainda oferecer um pedaço pra você. Ela sabia, tinha ido me visitar no hospital. Eu acho que é porque não estão acostumados ainda. Hoje em dia ela não faz [...], mas o resto da minha família continua dando [...]. O meu irmão, às vezes, come doce em casa, na minha frente. Eu fico com muita raiva, parece que ele come pra mim ver ele comendo.

As pessoas muitas vezes podem não ter consciência da importância de uma dieta adequada para este adolescente, tampouco saber o valor de sua contribuição no processo de aceitação e adaptação à sua nova realidade. Aqueles que interagem mais intimamente com o adolescente precisam, em algumas situações, adequar seus próprios hábitos de maneira a contribui e facilitar este processo, evitando, assim, trazer mais sofrimento ao mesmo.

É de fundamental importância que a família deste adolescente seja incluída no processo educativo, pois é ela quem representa a principal rede de apoio ao mesmo. É preciso que os familiares estejam capacitados e sensibilizados para os cuidados com o adolescente e, sobretudo, que se tornem conscientes de sua importância no processo de enfrentamento da doença.

O adolescente valoriza e reconhece o cuidado que a família tem com relação à sua alimentação e a preocupação em preparar refeições adequadas às suas necessidades. Ele sabe que esta é uma ajuda valiosa para o seguimento de sua dieta, e coloca que a grande dificuldade está em frequentar os espaços fora de casa, onde precisa lidar com o fato de ver as pessoas comendo e ter que se manter longe dos alimentos prejudiciais à sua saúde. Outro aspecto apontado nos depoimentos foi a dificuldade na convivência com irmãos menores, devido ao fato de doces e guloseimas, alimentos estes que são restritos em sua dieta, ficarem à disposição dentro de casa.

\section{IC - A alimentação em casa}

DSC: [...] em casa até que não é difícil. É ruim quando tu vai sair e vê alguém comendo, em casa a minha mãe cuida [...] às vezes ela come até das minhas comidas. Já o meu irmão [mais novo], ele come de tudo, ele come o doce dele, a gente é obrigada a comprar né, ai tá lá, pra gente olhar, porque eu também não acho justo ele não poder comer por causa de mim. Ele também precisa de doce. Ele é uma criança. Aí fica ali à vista, pra mim ver, aqueles potes de nutella, aqueles chocolates, nescau, é tudo assim.

Com o passar do tempo, o adolescente vai aprofundando o conhecimento e entendimento da doença, tornando-se mais seguro e assumindo cada vez mais uma postura ativa e consciente frente às situações de limitação impostas. Ele aprende a conviver sem determinados alimentos, controlar sua quantidade, optar por outros alimentos e compreender a importância do auto cuidado para a sua saúde. ${ }^{18}$

\section{IC - Com o tempo, fui aprendendo a me controlar,} hoje consigo lidar melhor com minha alimentação

DSC: [...] agora eu acho que é mais fácil [...] já aprendi mais sobre a doença. Hoje eu consigo lidar melhor [...] às vezes eu ainda tenho aquela vontade [...], mas consigo me controlar [...]. Quando a gente sai, não tomo sorvete, refrigerante é light ou diet [...]. No aniversário da minha amiga a gente foi na pizzaria, aí eu comi [...] o que eu podia e no horário que eu podia [...] tem coisas que nem me incomoda mais [...] também não vou morrer por causa de não comer um doce, só que tem aqueles doces também que não dá pra não querer. Eu acho que as outras coisas são mais fáceis, eu sou mais rígida com a minha alimentação [...], pra não passar fome e nem passar mal [...] mas tantas vezes que eu já fiquei internada aqui, e tantas noites que eu já não dormi bem, que eu já me acostumei, já botei na minha cabeça que é com a alimentação que eu tenho que cuidar, e de mim [...] pra não ter problemas depois [...].

As experiências vividas, o conhecimento adquirido e o aumento no nível de maturidade fazem com que o adolescente aprenda a lidar melhor com sua doença. Ele percebe que mesmo tendo que conviver com restrições alimentares é possível programar e balancear suas refeições de maneira a poder incluir em sua dieta o consumo de alimentos restritos, ainda que de maneira mais controlada e reduzida, de forma a não prejudicar sua saúde. Esta possibilidade permite que ele exerça maior controle e administração sobre a sua doença, tornando-se mais seguro e adquirindo autonomia de maneira responsável. Assim, ele percebe que é possível conduzir sua vida sem ser vencido pela doença. 
IC - Tenho estratégias para poder comer o que quero

DSC: [...] quando eu sei que vou comer em algum lugar, eu cuido antes, como menos, e depois também, para poder comer naquela hora [...] como mais salada na hora do almoço e menos carboidrato [...] pra comer à tarde, e à noite [...] uma salada só com frango, carne. Também tem às vezes quando tá boa [a glicemia], aí minha mãe deixa eu comer alguma coisa [...].

A descontração também esteve presente nas falas dos adolescentes, refletindo o enfrentamento positivo da situação apesar das dificuldades enfrentadas. Tal atitude demonstra a busca de soluções para os problemas, de forma criativa e diferenciada. ${ }^{19}$

\section{IC - Faço brincadeiras com minha dieta}

DSC: [...] não sei o que eu acho diferente, não sei explicar [...]. Com os meus amigos é a mesma coisa, normal [...] às vezes eles me oferecem algum doce, mas é por esquecimento, daí já pedem desculpa, quando eles tomam refri eu peço diet e eles brincam "a vai tomar diet pra não engordar". Eu falo "claro, vocês acham que é fácil manter esse corpinho?" (risos).

O apoio dos amigos e o fato de terem continuado a tratá-lo da mesma maneira, fazendo brincadeiras com sua dieta, foram colocados como aspectos favoráveis, fortalecendo o sentimento de aceitação e inserção no grupo e tornando mais leve a convivência com as restrições alimentares.

\section{Terceira categoria: a alimentação na escola}

\begin{tabular}{|l|l|l|}
\hline a) Levo de casa & $\begin{array}{l}\text { b) Não levo, pois tenho vergonha (en- } \\
\text { tão eu compro) }\end{array}$ & $\begin{array}{l}\text { c) Não levo, pois tenho vergonha (en- } \\
\text { tão não como) }\end{array}$ \\
\hline $\begin{array}{l}\text { d) Não levo, pois não há espaço na } \\
\text { mochila }\end{array}$ & $\begin{array}{l}\text { e) Não como, pois não tenho fome de } \\
\text { manhã }\end{array}$ & \\
\hline
\end{tabular}

Quadro 3 - Idéias centrais da categoria - A alimentação na escola

Este tópico mostrou ter grande influência na vida dos adolescentes com doença crônica. Dos entrevistados, apenas um adolescente referiu alimentar-se corretamente durante o período em que se encontra na escola.

\section{IC - Levo de casa}

DSC: [...] eu faço o dextro pra ver como está e se for preciso eu faço a insulina. Eu levo lanche, pão com presunto com queijo e salada. Sempre levo assim, aí eu tomo a insulina.

A escola é um espaço onde o adolescente possui a liberdade de escolher suas amizades, fazer projetos e conviver com colegas da mesma faixa etária. É onde, de certa maneira, ele deixa de ser criança. Este espaço é de grande importância na busca por autoafirmação e auto identidade. Neste contexto, a identificação em grupo torna-se essencial. O adolescente deseja ser igual aos demais, e isto também inclui sua alimentação. Ele busca a aceitação dos colegas, admira e deseja fazer parte daquele grupo. É pertencendo a um grupo, sendo igual aos seus integrantes que o adolescente ganha status e melhora sua autoestima. Por outro lado a incapacidade de um membro do grupo pode ser vista como uma ameaça à uniformidade estabelecida, ${ }^{4}$ assim, por medo de ser diferente e rejeitado, o adolescente portador de doença crônica acaba por esconder suas reais necessidades.

\section{IC - Não levo, pois tenho vergonha (então eu compro)}

DSC: [...] eu compro calzone, água de limão. Antes eu fazia lanche, mas era o lanche que eu levava de casa. Eu comia fruta, agora não, porque eu tenho vergonha, ninguém leva. A minha mãe disse que antes eu era mais cuidadosa [...]. Eu acho que é por causa da idade né, a gente fica com vergonha [...]. Levar de casa eu não consigo [...] ninguém leva. Antes eu ia toda casqueira pra escola. Eu não gosto de levar nada, depois em casa eu como melhor.

\section{IC - Não levo, pois tenho vergonha (então não como)}

DSC: [...] não lancho, não levo de casa, não gosto, $e$ lá também não como. É tudo coisa que eu não posso. Almoço bem e depois eu como quando chego em casa, eu acho que não precisa.

Esta situação representa grande perigo à saúde do adolescente portador de doença crônica, pois ou ele acaba consumindo alimentos que não deveriam fazer parte de sua dieta ou então permanece por longos períodos sem se alimentar. 
O adolescente percebe as consequências geradas pelo erro alimentar e tem consciência de como deveria estar conduzindo sua dieta. No entanto, o sentimento de indestrutibilidade típico desta fase, interfere no processo de adesão aos cuidados necessários com a doença crônica. O adolescente acredita ser invulnerável às consequências futuras de atos e comportamento errados do presente, e a doença que deveria comprometer esta idéia de indestrutibilidade, muitas vezes só faz aumentar o desafio. ${ }^{20-21}$

Um fator que poderia auxiliá-los na manutenção de uma alimentação mais adequada às suas necessidades seria a existência de opções mais saudáveis de lanche no ambiente escolar. Tais situações demonstram a importância do preparo da escola como um todo e reforçam a necessidade da atuação do profissional de saúde neste ambiente.

\section{IC - Não levo, pois não há espaço na mochila}

DSC: [...] minha glicemia dá alta à noite. É porque eu fico muito tempo sem comer, porque eu não levo lanche pra escola. Aí quando chego em casa, eu como muito [...] não como as frutas que tem que comer [...] não levo pra escola porque minha mochila é muita pesada, tem muito livro, não dá pra colocar o lanche. E na escola só tem salgadinho, chocolate, bolo, doce [...]. Eu chego com muita fome em casa, e também já aconteceu de me dar hipoglicemia na escola.

\section{IC - Não como, pois não tenho fome de manhã}

DSC: [...] na escola eu não costumo lanchar [...] tomo café em casa antes de sair e depois eu almoço quando chego. É ruim pra mim porque eu fico muito tempo sem comer e daí quando eu como, eu como demais, mas eu não consigo comer de manhã [...]. Teve uma semana que me deu hipoglicemia todo dia [...]. O problema é que chego em casa e como pelas horas que eu não comi. Mas não adianta eu levar nada, não dá fome.

Os adolescentes relataram diversos motivos para justificar seu descuido com a alimentação no ambiente escolar. A grande maioria demonstrou saber dos prejuízos causados à sua saúde e muitos já passaram por descompensações e momentos de exacerbação da doença devido a tal atitude. No entanto, o que se percebe é que eles continuam mantendo o mesmo comportamento, independente dos malefícios causados. Esta situação mostra o quanto é complexo mudar hábitos alimentares e, principalmente, seguir uma dieta diferenciada na adolescência. Tal dificuldade é ainda mais relevante quando se encontram em ambientes de convívio com outros adolescentes, pois, muitas vezes, para fazer parte do grupo e não ser diferente dos colegas, este adolescente acaba tomando atitudes que isoladamente não tomaria, ${ }^{21}$ colocando sua saúde em risco.

\section{CONSIDERAÇÕES FINAIS}

A doença provoca mudanças significativas no cotidiano dos adolescentes. Estes precisam se ajustar a uma realidade permeada por restrições e necessidades que afetam diversas áreas de sua vida, alterando a realização de uma série de atividades da vida diária.

Neste contexto, a escolarização é um dos aspectos afetados, visto que a doença interfere na frequência às aulas e estabelece dificuldades na aprendizagem. É preciso que a escola e o hospital atuem de maneira conjunta, estabelecendo uma relação de diálogo e trabalhando a referência e contrareferência. $\mathrm{O}$ adolescente necessita de uma rede de apoio que proporcione condições favoráveis à continuidade do seu aprendizado, especialmente durante o período em que se encontra hospitalizado. O profissional que presta cuidado a este adolescente deve estar atento a esse aspecto e formas alternativas de ensino devem ser pensadas e colocadas em prática no ambiente hospitalar e escolar.

$\mathrm{O}$ conhecimento dos fatores que dificultam a adaptação escolar e desmotivam o adolescente portador de doença crônica é importante para que se preste um cuidado mais amplo ao mesmo, considerando ações realmente efetivas para a promoção do crescimento e desenvolvimento deste adolescente nos diversos contextos em que se encontra inserido. A grande distância existente entre escola/educação e hospital/saúde impede a construção de um cuidado holístico, que passa obrigatoriamente pelo entendimento e pela compreensão de que a educação e o cuidado à saúde são processos entrelaçados e que exigem, assim, a construção de pontos de aproximação entre a instituição hospitalar e a escolar.

Considerando que o adolescente com doença crônica vivencia situações complexas em seu cotidiano, é importante que os profissionais envolvidos em seu cuidado conheçam suas demandas e busquem desenvolver ações que contribuam para a redução do estresse e proporcionem um melhor enfrentamento das situações impostas pela doença.

As restrições alimentares são outro aspecto que interfere diretamente no cotidiano deste 
adolescente. Conhecer os significados destas restrições, que por vezes vão além do fato de precisar reprimir sua vontade, fará com que o profissional de saúde consiga estabelecer uma comunicação e uma relação mais próxima com esse adolescente e as pessoas que com ele convivem, tornando mais fácil e efetiva a incorporação das orientações referentes aos bons hábitos alimentares.

Os profissionais de saúde devem ter consciência da complexidade que envolve a vivência da doença crônica durante a fase da adolescência e da importância em conhecer e valorizar os significados dessa experiência para o adolescente, visto que são esses significados que irão direcionar suas ações e determinar a eficácia do enfrentamento de sua condição.

\section{REFERÊNCIAS}

1. Maffesoli M. O conhecimento comum: introdução à sociologia compreensiva. Porto Alegre (RS): Sulina; 2007.

2. Maffesoli, M. O mistério da conjunção: ensaio sobre comunicação, corpo e socialidade. Porto Alegre (RS): Sulina, 2005.

3. Lira, GV, Nations, MK, Catrib, AMF. Cronicidade e cuidados de saúde: o que a antropologia da saúde tem a nos ensinar? Texto Contexto Enferm. 2004 Jan-Mar; 13(1):147-55.

4. Hockenberry MJ, Wilson D, Winkelstein ML. Wong: fundamentos de enfermagem pediátrica. $7^{\mathrm{a}} \mathrm{ed}$. Rio de Janeiro (RJ): Elsevier; 2006.

5. Vieira MA, Lima RAG de. Crianças e adolescentes com doença crônica: convivendo com mudanças. Rev Latino-am Enfermagem [online]. 2002 [acesso 2010 Abr 10]; 10(4):. Disponível em: http:/ / www. scielo.br/scielo.php?script=sci_arttext\&pid=S0104 11692002000400013\&lng=pt.

6. Almeida MI, Molina RCM, Vieira TMM, Higarashi $\mathrm{IH}$, Marcon SS. O ser mãe de criança com doença crônica: realizando cuidados complexos. Esc Anna Nery Rev. Enferm [online]. 2006 [acesso 2010 Jan 24]; 10(1) Disponível em: http:/ / www.revenf.bvs. br/scielo.php?script=sci_arttext\&pid=S1414814520 06000100005\&lng=pt.

7. Pizzignacco TMP, Lima RAG. O processo de socialização de crianças e adolescentes com fibrose cística: subsídios para o cuidado de enfermagem. Rev Latino-am Enferm [online]. 2006 [acesso 2008 Nov 12]; 14(4). Disponível em: http:/ / www.scielo. br/scielo.php?script=sci_arttext\&pid=S0104116920 06000400015\&lng=pt\&nrm=iso.

8. Araújo YB, Collet N, Moura FM, Nóbrega RD. Conhecimento da família acerca da condição crônica na infância. Texto Contexto Enferm [online].
2009 [acesso 2009 Out 20]; 18(3). Disponível em: http:/ / www.scielo.br/scielo. php?script=sci arttext\&pid=S0104-07072009000300013\&lng=en.

9. Mead GH. Espiritu, persona y sociedad: desde el punto de vista del conductismo social. Buenos Aires (AR): Editorial Paidos;1972.

10. Minayo MC. Pesquisa social: teoria, método e criatividade. Petrópolis (RJ): Editora Vozes; 2008.

11. Lefreve F, Lefreve AMC. O discurso do sujeito coletivo - um novo enfoque em pesquisa qualitativa (desdobramentos). $2^{\mathrm{a}}$ ed. Caxias do Sul (RS): Editora Educs; 2005.

12. Campolina LO, Oliveira MCSL. Cultura escolar e práticas sociais: episódios cotidianos da vida escolar e a transição para a adolescência. Educ. Pesqui. [online]. 2009 [acesso 2011 Mai 04]; 35(2); 35(2):369-80. Disponível em: http:/ / www.scielo. br / scielo.php?script $=$ sci_arttext\&pid $=$ S151797022009000200010\&lng=en\&nrm=iso

13. Nóbrega RD, Collet N, Gomes IP, Holanda ER, Araújo YB. Criança em idade escolar hospitalizada: significado da condição crônica. Texto Contexto Enferm [online]. 2010 Jul-Set [acesso 2011 Abr 14]; 19(3):425-33. Disponível em: http://www.scielo. br/scielo.php?script=sci_arttext\&pid=S010407072010000300003\&lng=en.

14. Ministério da Educação (BR), Secretaria de Educação Especial. Política Nacional de Educação Especial na Perspectiva da Educação Inclusiva. Brasília (DF): MEC, SEESP; 2007.

15. Souza SR, Oliveira ICS. Entre desafios e possibilidades: estratégias para ensinar a cuidar em enfermagem do adolescente com câncer. Rev Esc Enferm USP [online]. 2007 Set [acesso 2011 Abr 15]; 41(3):508-12. Disponível em: http:/ / www. scielo.br/scielo.php?script=sci_arttext\&pid=S008062342007000300023\&lng=en.

16. Nunes MDR, Dupas G. Entregando-se à vivência da doença crônica com o filho: a experiência da mãe da criança/adolescente diabético. Texto Contexto Enferm. 2004 Jan-Mar; 13(1):83-91.

17. Damião EBC, Pinto CM. Being transformed by illness: adolescents' diabetes experience. Rev Latino-am Enfermagem [online]. 2007 [acesso 2008 Nov 12]; 15(4). Disponível em: http:/ / www. scielo.br/scielo.php?script=sci_arttext\&pid=S0104$11692007000400008 \& \operatorname{lng}=$ pt\&nrm=iso

18. Moreira PL, Dupas G. Vivendo com o diabetes: a experiência contada pela criança. Rev Latino-am Enfermagem. 2006 Jan-Fev; 14(1):25-32.

19. Santos ECB, Zanetti ML, Otero LM, Santos MA. O cuidado sob a ótica do paciente diabético e de seu principal cuidador. Rev Latino-am Enfermagem [online]. 2005 [acesso 2009 Nov 09]; 13(3):397-406. Disponível em: http:/ /www. scielo.br/scielo.php?script=sci_arttext\&pid=S0104 $11692005000300015 \& \operatorname{lng}=p t$ 
20. Nogueira KT. Avaliação da qualidade de vida entre adolescentes asmáticos [tese na Internet]. Rio de Janeiro: Universidade Estadual do Rio de Janeiro, Instituto de medicina Social; 2007 [acesso $2008 \mathrm{Nov}$ 10]. Disponível em: http://www.tesesims.uerj.br/
lildbi/docsonline/3/1/413-Katia_Telles.pdf

21. Santos MFO, Elias VRS. Desenvolvimento psicossocial normal. In: Coutinho MFG, Barros RR. Adolescência uma abordagem prática. São Paulo (SP): Editora Atheneu; 2001. 